the early period he deals with; but I must leave it to himself, or any other of your contributors who will kindly give us some farther information on the point.

$$
\text { I am, Sir, }
$$

Your most obedient servant,

Aberdeen, 24th November, 1862.

H. AMBROSE SMITH.

\title{
ON MR. YOUNGER'S SCHEME FOR THE ASSURANCE OF DETERIORATED LIVES.
}

To the Editor of the Assurance Magazine.

SiR,-My attention has been directed to Mr. Yonnger's paper in your last Number (p. 268), on a scheme for the assurance of diseased and deteriorated lives, and I shall be glad to be allowed to make a few remarks on it.

The usual mode of dealing with deteriorated lives is to treat them as if so many years older than their actual age, the effect being the imposition of an additional amount of preminm, which may or may not be commuted into a reversionary deduction. Mr. Younger is dissatisfied with this mode of treatment, and he propounds a scheme of his own, with a view to obviate his objections to that at present in use.

Mr. Younger's main position is, that the decision of "the medical officer [which regulates the number of years to be added to the age of the life, and, consequently, the amonnt of the extra preminm], if incorrect, is far more likely to be in favour of the Company than otherwise"; and upon this, as a foundation, he erects his superstructure. Retaining the extra premium, imposed in accordance with the medical report, he proposes:-

1. That this preminm shall be payable, not during the whole of the after-lifetime, but only during a portion of it.

2. That it shall not be payable even during the term in question, unless the assured die during the said term. And,

3. Commuting the preminm thas curtailed and rendered contingent into a whole-life reversionary deduction, he proposes, finally, to restrict the duration of this deduction to the term already referred to.

Add to all this that Mr. Younger, in his valuations and commutation, uses the real, and not the increased age, and it will be strongly surmised that the concessions enumerated are vastly more than sufficient to meet a presumed likelihood that the medical report, if incorrect, errs in favour of the Office.

Let us examine a particular case. I take at random the first given by Mr. Younger-a life of 30 , which is estimated by the medical officer as deteriorated to the extent of five years, and on which, accordingly, an additional premium of $7 s .2 d .=\mathbf{3 5 8 3 3 3}$ per cent. is imposed. The present value of this premium (Carlisle 4 per cent.), as at age 35 , is $6 \cdot 1065$. Mr. Younger, for this premium, substitutes a reversionary deduction of f6. $12 s .=6 \cdot 600$, during the first 34 years-the present value of which is 1.7086. If, with Mr. Younger; we nse the real age, the values come out 6.3970 and 1.4568 respectively, exhibiting a still greater disparity. The 
medical report is thus, in fact, all but nullified; and it is hence easy to predict the consequences to an Office which should adopt $\mathrm{Mr}$. Younger's scheme. Mr. Younger can hardly have instituted such a comparison as the above previous to propounding his scheme. If he had, I cannot believe that he would have considered the striking off of 77 per cent. from the penalty for deterioration, all round, the right thing to do in compensation of a possible error in a few cases, in farour of the Office.

The problem implied in Mr. Younger's scheme possesses interest as involving an allocation- $I$ cannot call it payment-of premium which has not been heretofore considered. For that reason, therefore (as a nseful exercise), and for others besides, I here give a solution of it.

\section{Problem.}

A temporary preminm, $\pi$, to last $t$ years, is exigible on $(x)$, but is to be payable only if the life fail during the said term of $t$ years. The periodical payment of such a premium being impracticable, it is to be commuted into a temporary reversionary deduction, $V$, for the same term of $t$ years, from a whole life assurance on $(x)$, which assurance may be one either already subsisting, or to be now constituted. Required V.

Solution.-A premium exigible as described, as a little consideration will serve to show, is the same thing, so far as pecuniary result is concerned, as the same premium, $\pi$, payable during $t$ years, and subject to return, with componnd interest, at the end of the term, if $(x)$ shall be then alive.

The present value of the temporary premium is

$$
\frac{\pi \mathrm{N}_{x-1 \mid t}}{\mathrm{D}_{x}}
$$

and the return being $\pi(1+r)(A)_{i}$, where $(A)_{t}$ is the tabular amount of an annuity certain of $£ 1$ for $t$ years (the factor $1+r$ adapting it to the case of payment in advance), its present value is

$$
\frac{\pi(1+r)(\mathrm{A})_{t} \mathrm{D}_{x+t}}{\mathrm{D}_{x}} \text {, or } \frac{\pi\left[(\mathrm{A})_{t+1}-1\right] \mathrm{D}_{x+t}}{\mathrm{D}_{x}}
$$

Hence the value, subject to the return, is

$$
\frac{\pi\left\{\mathrm{N}_{x-1 \mid t}-\left[(\mathrm{A})_{t+1}-1\right]\right.}{\mathrm{D}_{x}} \underline{\left.\mathrm{D}_{x+t}\right\}}
$$

Equating this to

$$
\frac{\mathrm{VM}_{x \mid i}}{\mathrm{D}_{x}}
$$

the present value of the deduction, we get

$$
\mathrm{V}=\frac{\pi\left\{\mathrm{N}_{x-1 \mid t}-\left[(\mathrm{A})_{t+1}-1\right] \mathrm{D}_{x+t}\right\}}{\mathrm{M}_{x \mid t}}
$$

Applying this to the foregoing example, where $x=30, t=34$, and $\pi=\cdot 358333$, we find for $\mathrm{V}, 9 \cdot 3784$. Mr. Yonnger has $6 \cdot 600$, the difference arising from his having, as already stated, determined the dednction as if it were to last for life, and then arbitrarily restricted its duration to 34 years. 
Writing the above expression for the value of the premium, thus,

$$
\frac{\pi\left\{\mathrm{N}_{x-1}-\left[\mathrm{N}_{x+t-1}+\overline{(\mathrm{A})_{t+1}-1} \cdot \mathrm{D}_{x+t}\right]\right\}}{\mathrm{D}_{x}}
$$

we see at once the nature and the effect of Mr. Younger's dealing with the medical report. The first portion, $\pi \mathrm{N}_{x-1} \div \mathrm{D}_{x}$, is the value of the preminm arising from the medical officer's estimation of the risk, equal (if, with Mr. Younger, we erroneously used the real age) to 6.3970 ; and the remaining portion, $\pi\left\{\mathrm{N}_{x+t-1}+\left[(\mathrm{A})_{t+1}-1\right] \mathrm{D}_{x+t}\right\} \div \mathrm{D}_{x}$, is the value of the portion of this preminm that $\mathrm{Mr}$. Younger abandons, equal to $\mathbf{4} 3269$. And this is irrespective of his subsequent curtailment of the duration of $V$.

Mr. Younger's expression for the value of the premium is reducible to that given above. It is needless to occupy space by showing it.*

It may interest some of the readers of the Magazine if $I$ add a solution of the problem according to the old, and now almost disused, method.

That a premium will become dne in respect of the $n$th year will depend on the concurrence of these two events; first, that $(x)$ enters on that year, the probability of which is, $p_{x \cdot n-1}$; and, secondly, that $(x+n-1)$ will not attain the age $x+t$, the probability of which is, $1-p_{x+n-1 . t-n+1}$. The probability of the compound event therefore is,

$$
p_{x n-1}\left(1-p_{x+n-1, n+1}\right)=p_{x n-1}-p_{x t}
$$

Maltiplying by $\pi v^{n-1}$ (the payments being due at the commencement of the year), and summing from 1 to $t$, we obtain for the valne of the premium,

$$
\pi\left(1+a_{x t-1}-p_{x t} \frac{1-v^{t}}{1-v}\right)
$$

which may be put in either of the forms,

$$
\begin{array}{r}
\left.\pi\left\{1+a_{x t-1}\right\rceil-p_{x t}(1+r)(a)_{t}\right\}, \\
\text { or } \left.\pi\left\{1+a_{x . t-1}\right\rceil-p_{x .}\left[(a)_{t-1}+1\right]\right\},
\end{array}
$$

where $(a)_{t}$ and $(a)_{t-1}$ denote the tabular present values of annuities certain of $f 1$ for $t$ and $t-1$ years respectively.

To return for a moment to the scheme: Mr. Younger assumes, for the purposes of his investigation, that the incorrectness of the medical report is established, if the life reported on live over the term of years that he calls its "expectation." Mr. Younger knows theoretically that this is not true, for he admits as much. He nevertheless uses the hypothesis as if it were true, and we have seen the result. But I go a great deal further than a simple denial of the hypothesis, and $I$ say that it is maintainable that no amount of survivance on the part of a particular life, although extending to the utmost limit of haman existence, will suffice to prove that there was not, at the date of the medical report, sufficient ground for the relegation of that life to a class of a greater age than the age assigned by the date of its birth. If, in consequence of increased care (which is frequently engendered by delicacy of constitution), or from any other cause, the life in question should, contrary to anticipation, attain a good old age, the case must be

* Mr. Younger, like some other writers, denies himself the use of the very convenient symbol $v$, equivalent to $1 \div(1+r)$, or $(1+r)^{-1}$. In consequence, his expressions are more cumbrous than they need have been. 
considered as just one of those, the decision of which in favour of the Office, enables it to meet the claims arising on account of those that are decided against it. Having stood the risk of an adverse decision, the Office must not be called upon to surrender the consideration in respect of which it undertook that risk.

Mr. Younger intimates that one object he proposed to himself in the devising of his scheme was to exhibit a less value of the measure of deterioration than that exhibited by the existing method. The simplest way of doing this would have been to strike off a percentage from the result of the usual method, which way, moreover, would bave had the further advantage of letting us know exactly what we were about. This, Mr. Younger's way of proceeding does not do. It is too complex for that. In fact, it is apt to remind one of the proceedings of the scientific tailors of Laputa, who, disdaining the use of a tape for the measuring of their customers, employed a sextant instead. The customers were, to be sure, very badly fitted. But what of that? The process was conducted on strictly seientific principles.

$$
\text { I am, Sir, }
$$

Yours most obediently,

Camden Town, 3rd December, 1862.

P. GRAY.

\section{PROFESSOR DE MORGAN'S QUERY ABOUT INTEREST ACCOUNTS.}

To the Editor of the Assuranee Magazine.

Sir, - Under the head of "Notes and Queries," in your Magazine for October, I find a notice by Professor De Morgan of a mismanaged interest account.

The Professor does not state the method his friend followed; so with your permission I shall endeavour to point out what has to be considered in making up an interest account of the nature described, on equitable prineiples-the course the debtor most likely followed-and the errors he fell into.

When money is lent at a certain rate of interest, no dates for the payment of such interest being mentioned, it is understood to be paid once a year; and if interest falls in arrear, and no penalty has been mentioned in the agreement, the least that can in equity be expected of the debtor is that he pay interest at the same rate on the arrears.

In framing an ordinary account current it is usual to calculate the interest on each Dr. and Cr. balance for the time it exists (within a year), keeping a note of the Dr. and Cr. interest, and to add or deduct, as the case may be, the difference at the end of each year. If interest be charged and allowed at the same rate, this method is the same as charging interest on each advance, and allowing interest on each payment, from the date it is made to the end of the year. A new accounting then commences, and the process is carried on from year to year during the continuance of the account. If there is but one payment made in each year, and that on the day the interest falls dne, this process becomes similar to that described by Professor De Morgan-interest for the period is added to the principal, and the payment just made deducted; and this is the proper plan, whether the payment exceeds the interest or not. It would thns appear that the 